\title{
Living with a Vacuum Cleaning Robot
}

\section{A 6-month Ethnographic Study}

\author{
Julia Fink • Valérie Bauwens • Frédéric Kaplan • \\ Pierre Dillenbourg
}

Accepted: 2 May 2013 / Published online: 13 June 2013

(c) Springer Science+Business Media Dordrecht 2013

\begin{abstract}
Little is known about the usage, adoption process and long-term effects of domestic service robots in people's homes. We investigated the usage, acceptance and process of adoption of a vacuum cleaning robot in nine households by means of a six month ethnographic study. Our major goals were to explore how the robot was used and integrated into daily practices, whether it was adopted in a durable way, and how it impacted its environment. We studied people's perception of the robot and how it evolved over time, kept track of daily routines, the usage patterns of cleaning tools, and social activities related to the robot. We integrated our results in an existing framework for domestic robot adoption and outlined similarities and differences to it. Finally, we identified several factors that promote or hinder the process of adopting a domestic service robot and make suggestions to further improve human-robot interactions and the design of functional home robots toward long-term acceptance.
\end{abstract}

Keywords Domestic robots · Ethnographic study · Human-Robot interaction - Social issues in robotics . Long-term interaction · Adoption of technology

J. Fink $(\bowtie) \cdot$ V. Bauwens · F. Kaplan · P. Dillenbourg

Computer-Human Interaction in Learning and Instruction (CHILI), Ecole Polytechnique Fédérale de Lausanne (EPFL), Rolex Learning Center, Station 20, 1015 Lausanne, Switzerland e-mail: julia.fink@epfl.ch

\section{Bauwens}

e-mail: valerie.bauwens@epfl.ch

F. Kaplan

e-mail: frederic.kaplan@epfl.ch

P. Dillenbourg

e-mail: pierre.dillenbourg@epfl.ch

\section{Introduction}

With domestic service robots entering people's homes, it becomes increasingly important to understand the process of long-term adoption of these devices, taking into account user needs, characteristics of the home, and the (social) impact that these devices can have on the home ecosystem [11]. Still little is know about these aspects, despite the fact that several million units of domestic service robots have already been sold (mostly vacuum cleaning robots). To date, only few studies investigated Human-Robot Interaction (HRI) in homes over a longer period of time. However, these kind of real-world studies can provide interesting insights into usage and experience from a user point of view, and help to identify factors promoting and hindering adoption. By understanding better how people use and adopt domestic service robots, the functionality, user interaction and general design could be improved toward the goal of making domestic service robots useful, usable, and acceptable everyday tools. Studies investigating HRI during a longer period of time are also crucial, as it has been recognized that novelty plays a role and that interactions with technologies change over time and with growing experience $[1,8,11,18,30,33]$.

It is our aim to study the adoption of domestic robots and explore niches for this technology, addressing practical problems in daily lives of humans. As a starting point, we took the possibility of using a commercially available vacuum cleaning robot (iRobot's Roomba) for a 6-month ethnographic study with nine households using the robot. To the best of our knowledge, no such study has been conducted in Europe so far. Our study contributes to a better understanding of long-term implications in HRI in two ways.

First, findings contribute as itself to the limited number of long-term studies on HRI. We provide detailed insights into what happens when a functional robot like the Roomba is deployed in a home, with respect to: 
- people's cleaning routine and how it was affected by the introduction of the vacuuming robot (Sect. 4.1)

- how the physical and social context of the home impacts the usage of and interaction with the domestic service robot (Sect. 4.2)

- people's understanding of robots in general, their expectations and perception of a domestic service robot, and social activities related to the robot (Sect. 4.3)

- initial reactions to the robot and its adoption, along with factors related to this process (Sect. 5)

- implications for the acceptance of robots in domestic environments (Sect. 6)

Second, our work adds in a meaningful way to an initial framework of long-term acceptance of robots in homes, namely the 'Domestic Robot Ecology' (DRE) [33], along which we analyze and integrate our observations. The DRE is based a long-term field study with 30 households in the US. We carried out a similar study, with similar methodology, but in a culturally different context using different models of the same domestic service robot. By this, we provide new data to the framework and are able to show major similarities and interesting qualitative differences. Consequently, our work contributes also to making the DRE framework more robust and holistic.

Overall, the novelty of our work lies not in the experimental setup but in the way the data is analyzed and integrated in an existing framework of domestic robot adoption.

\section{Related Work}

Roomba is one of the most widely deployed vacuum cleaning robots and has been used in a series of studies focusing on user needs [31], design and personalization of home technologies [32], demographic profiles of robot owners [29], social implications of domestic robots [10, 11, 28], and long-term adoption [30, 33]. In the following we first give an overview of previous work that explored usage, user profiles, and the adoption of domestic service robots, and then describe how our study can contribute to this.

People's Expectations of Domestic Robots Sung et al. and Forlizzi et al. have conducted interviews [31], surveys [29], and ethnographic research [11] with Roomba owners. They found that within their concept of robots, people distinguished between 'Roomba' and the great mass of 'other robots' [11]. While people's expectations of robots in general were high, they were rather low for the Roomba and its practical functionality [11]. Nevertheless, participants expected a domestic robot to be intelligent and able to learn. The important point for our work is that, people's specific expectations of Roomba have been shown to shape their initial experience with it which is in turn important for adoption. This makes it essential to assess participants' attitudes first in order to better understand their reaction.

User Profiles and Usage of Domestic Service Robots Sung et al. [29] assessed demographic profiles and usage patterns in a survey among more than 350 Roomba owners. Data revealed that Roomba users were equally likely men or women, and tended to be younger with higher levels of education or technical backgrounds [29]. Half of the Roomba owners who took part in the survey lived with one or more pets and those with children at home expressed greater satisfaction with the robot's performance. This suggests that the composition of a household influences how people use and experience a domestic robot [10]. Concerning the usage of vacuum cleaning robots, Kim et al. discovered a discrepancy between the cleaning path participants in Korea used when manually vacuuming, and the paths chosen by vacuum cleaning robots [19]. Consequently, the authors suggest to adapt the robot's path planning to the specific area of a home and the according user needs, as the user tends to use area specific methods for vacuuming.

Domestic Robots can Impact Routines and Create Social Dynamics In terms of the impact on housekeeping, it has been shown that in comparison to a traditional vacuum cleaner (VC), the Roomba changed people's cleaning activities and how they used other tools [10]. The robot affected cleaning routines, by increasing cleaning activities, encouraging multi-tasking, collaboration, and making cleaning a concern for everyone in the home [11,33]. On one hand, the Roomba was described as "a tool to improve the cleanliness of the home" [11,33], though the majority of Roomba owners reported doing extra cleaning with the manual vacuum cleaner [29]. On the other hand, the robot enhanced (social) activities other than cleaning: It led people to adjust the physical environment or to create and remove obstacles. In both ethnographic studies with the Roomba, people engaged socially with the robot, such as by giving it a name, talking directly to it, or ascribing intentions and personality traits $[11,28,33] .^{1}$

Sung et al. further observed that people customized their Roomba (e.g. with drawing or putting stickers on it) to express its 'identity' (or gender) and show its value to the household [32]. Intimacy and positive emotional attachment, such as assigning an identity to the robot, led to greater acceptance of the product in general and the perceived usability [37]. These social aspects and their positive

\footnotetext{
${ }^{1}$ Social implications of home technologies and domestic robots, such as intimacy, affective quality, and emotional attachment have been studied in more detail $[10,22,28,37]$.
} 
effect have also been mentioned by others and in respect to different kinds of robots and technologies [5, 8, 28]. It is suggested that social factors in the usage of household technology are crucial to understand usage patterns and longterm acceptance [36, 40].

Novelty Effects with Robots and Long-Term Usage Novelty effects have been described with interactive technologies [22] and also in several long-term studies on HRI in non-domestic environments, such as workplaces [15, 20], schools [17, 18] or elder care centers [23]. However, also with domestic robots, long-term studies found that people's interest, engagement and fascination with the robot decreased over time [8,30]. Concerning long-term usage and the adoption of robots in homes, two ethnographic studies with the Roomba have been conducted in the US, involving 14 and 30 households respectively [10, 11,33]. These studies led to the development of an initial framework, the 'Domestic Robot Ecology' (DRE), which is proposed by Sung et al. [33]. The DRE applies a holistic view to the relationships that robots shape in the home and takes into account long-term effects. DRE is a first step towards a comprehensive understanding of HRI in a domestic environment.

Based on the interesting findings provided by the two major ethnographic studies with the Roomba in households in the US, we decided to add to this branch of research a similar study. We deployed recent models of Roomba in nine households in Switzerland.By this we take into account the specific context for which we aim to develop new robotic solutions in the future. A replication of Sung et al.'s longterm study with Roombas makes sense for the goal of exploring similarities and differences in the process of adoption in two culturally different regions. Since cultural differences seem to play a role in the perception of robots and HRI [1], and further Swiss homes might look and be organized/maintained differently than US homes [3], we also wanted to explore how far our findings can be integrated and analyzed in relation to the data from Sung et al./Forlizzi et $a l$., and the DRE initial framework of long-term acceptance of robots in homes, in particular. Consequently, the originality of our work mainly lies in the way our data is analyzed, namely taking the DRE framework into account and showing that it can be used as a tool to structure and understand the process of adoption of a domestic robot, also in a different context.

\section{Study Design}

We set up an ethnographic study with nine households to which we gave a Roomba vacuum cleaning robot (two different models, depending on whether the household owned a pet, see Table 1). It was our aim to investigate in a qualitative and explorative way how usage and experience evolved over time and study the impact on cleaning patterns. This requires a holistic understanding of the household's everyday routines, their cleaning activities, as well as their expectations of domestic service robots. Ethnography is a qualitative research method that attempts to generate a holistic account of cultures or groups of people, such as a household. Ethnography has already been applied to study HRI and long-term adoption of robots in homes [8, 10, 30]. In its origin, ethnography is a form of anthropological practice and both a methodology and perspective [3]. According to Bell, ethnography is considered a type of field work where the researcher spends time in and with the culture or peoples studied, participating in everyday life and attempting to make sense of the patterns of that culture [3]. We understand ethnography not in its traditional anthropological sense of 'going native' but as a research technique to obtain qualitative insights into what happens in the real world in contrast to a well defined but limited laboratory setting. Roboticists, engineers, and interaction designers acknowledge the rich insights qualitative research in real world environments can provide to inform future developments and refine design [8, 24, 33]. However, longitudinal ethnographic research brings along several challenges in terms of data acquisition, data structuring, and interpretation. These and other difficulties have also been outlined by Fernaeus et al. [8] and Sung et al. [30].

\subsection{Methodology}

The methodology applied to study long-term acceptance of a domestic robot needs to match the described difficulties and constraints created by the private nature of the home. Potentially relevant events can take place not only in a predefined space but within the whole social living space, as well as at times when the researcher is not present. However, using logging mechanisms or extensive video recording would create an unnatural setting which would not meet the goals of our study. Another challenge is to capture routines of cleaning activities. A routine commonly happens less consciously; it is consequently hard for participants to talk about it explicitly and thus it is difficult to investigate.

We addressed these difficulties by using a similar study design and methodology to that proposed by Sung et al. [30] and also inspired by how Forlizzi et al. set up their studies about cleaning in the home with and without the Roomba $[10,11]$. More concretely, we also used ethnographic methods, including home visits, a 'home tour', qualitative interviews, and cleaning diaries. Our study took place from March to October 2011 and was composed of five visits at each of the participating households:

1. Approximately one week prior to handing out the Roomba, we had an introductory visit and home tour at each home and got to know the household, people's routines and their attitudes towards robots. 
2. At our second visit, about one week after the first one, we brought the Roomba with us, interviewed people about their expectations and observed their initial reactions to the robot.

3. Approximately two weeks later, we came back to see how the household experienced Roomba and what it was used for. Prior to this visit, participants were asked to report their usage of the robot in a diary.

4. About two months after the Roomba was deployed, the households were visited again. We wanted to examine how usage and perception of the robot changed over time and how far the robot was integrated into everyday life. For ten days prior to this visit, householders completed a cleaning-diary.

5. A concluding visit was conducted about six months after we brought the Roomba to the household. This was to investigate changes in the usage patterns, to assess social dynamics, and whether the experience with the domestic robot changed people's perception of robots in general. Participants were again asked to fill out a cleaning-diary during ten days prior to the visit.

In terms of the methods used, we applied several qualitative as well as quantitative techniques. Data was collected at all households throughout the 6-month period, regardless whether they stopped using the robot for cleaning. At each visit, semi-structured qualitative interviews were conducted (44 interviews, each lasting 1-1.5 hours), audio-recorded and qualitatively re-transcribed. At each interview, participants were interviewed collectively and asked to describe how they used the robot (for cleaning and other activities), their satisfaction with it, and perceived benefits and constraints. The first visit also included a home tour where the household's main contact person showed us their technological equipment, cleaning tools, and spots in the home that they considered challenging to clean. By this we also learned about their conceptions of cleanliness and order [21]. At each visit, we collected field notes and photos or videos from the on-site observations. Prior to each visit (except the first one), each household filled out a daily diary to capture cleaning activities and Roomba usage. Self-reported data such as diaries have been used by others, such as for 'cultural probing' [12], in sociological research [27] as well as in previous studies with the Roomba [10]. We verified people's self-reported data through the interviews and observations. People's perception of the robot was quantified by a series of seven point Likert scales integrated into a small questionnaire to be filled out at each visit. Participants rated the robot in terms of intelligence, usefulness, ease of use, its impact on the household, fun, and emotional attachment, as well as overall impression. We adapted this questionnaire from Bartneck et al. [2] and Sung et al. [30]. The assessed aspects are relevant for describing people's perception of a robot and crucial for the adoption of technology [38]. To make it easier for participants to talk about their cleaning routines and their experience with the robot, we enriched the interviews with projective techniques such as 'Bubble Talk' [30], 'Day Reconstruction Method' [16], and drawing or tinkering activities. Participants generally appreciated these activities.

The ethnographic approach of going to the households combined with the described qualitative and quantitative research techniques worked well. It allowed us to gain detailed insights into how people were living with their robotic vacuum cleaner and helped us to understand the changes it evoked in some of the households. The before-mentioned activities during the interviews made the discussions more enjoyable and helped people to be natural and open with us. Nevertheless, it has to be mentioned that the preparation of these research tools required a lot of effort and we were happy to have the participation of a professional ethnographic researcher, who is one of the co-authors.

The gathered data was mostly analyzed in a qualitative way where two researchers studied the collected material related to the research topics, cleaning activities, and experience with the Roomba. We extracted relevant observations from field notes in several spreadsheets and organized them in chronological time-series as well as in topic-specific categories. This process was motivated by Grounded Theory [4] and a method for analyzing user behavior in home environment [13]. Later, data was integrated and analyzed according to the DRE framework of adoption [33]. Data from the cleaning diaries was translated in English (if necessary) and typed in a spreadsheet for a descriptive analysis. The paper-and-pencil diaries captured the following aspects of a cleaning/household task: day and date, time, relation to previous/following activity (if any; e.g. before guests arrived), duration, who carried out the task, which rooms/parts of the home were cleaned, what was cleaned (e.g. floors, windows, toilet, etc.) using which tools (e.g. towel, vacuum cleaner, brush, dish-washer, Roomba, etc.). These were all self-reported data that may be incomplete or biased by the nature of the study (i.e. people actually carry out more cleaning activities than usual because they consciously think about cleanliness as it is part of the study). However, we discussed cleaning tasks with the participants during the interviews to confirm and clarify some of the entries. Quantitative data from the Likert ratings was subjected to a statistical analysis. Preliminary results have been published [9].

\subsection{Participants/Sample}

As the goal of this study was to qualitatively explore how people live with a vacuum cleaning robot, we decided to select a diverse sample of households rather than focusing on one specific type. Households were recruited through word of mouth, a request distributed via e-mail, and an announcement in a school's newsletter. The call invited households with and without children and pets to participate in 
Table 1 Participants of 6-month ethnographic Roomba study; the cleaning strategy was determined from self-reported data in diaries and on-site observations; the adoption group refers to the degree of household use or adoption of the robot

\begin{tabular}{|c|c|c|c|c|c|c|c|}
\hline \# type & People, age & Pets & $\begin{array}{l}\text { House } \\
\text { type }\end{array}$ & $\begin{array}{l}\text { Cleaning } \\
\text { service }\end{array}$ & $\begin{array}{l}\text { Cleaning } \\
\text { strategy }\end{array}$ & $\begin{array}{l}\text { Roomba } \\
\text { model }\end{array}$ & $\begin{array}{l}\text { Adoption } \\
\text { group }\end{array}$ \\
\hline $\mathrm{H} 1$ single & $\mathrm{m}, 40$ & no & flat & no & spartan & 520 & adopter \\
\hline $\mathrm{H} 2$ single & $\mathrm{f}, 71$ & $\begin{array}{l}1 \mathrm{dog} \\
2 \text { turtles }\end{array}$ & house & yes & minimalistic & 563 PET & user \\
\hline H3 couple & $\begin{array}{l}\mathrm{f}, 62 \\
\mathrm{~m}, 58\end{array}$ & 2 cats & flat & no & minimalistic & 563 PET & user \\
\hline H4 family & $\begin{array}{l}\text { mother, } 43 \\
\text { father, } 47 \\
2 \text { girls, } 10,8\end{array}$ & 1 cat & house & yes & carer & 563 PET & user \\
\hline H5 family & $\begin{array}{l}\text { mother, } 45 \\
\text { father, } 45 \\
3 \text { girls, } 18,12,12 \\
\text { boy, } 15\end{array}$ & $1 \mathrm{dog}$ & house & no & carer & 563 PET & adopter \\
\hline H6 family & $\begin{array}{l}\text { mother, } 28 \\
\text { father, } 28 \\
\text { girl, } 5 \\
2 \text { boys, } 4,1 / 2\end{array}$ & 1 cat & house & yes & manic & 563 PET & adopter \\
\hline H7 family & $\begin{array}{l}\text { mother, } 29 \\
\text { father, } 34 \\
\text { boy, } 11 / 2\end{array}$ & no & flat & no & manic & 520 & rejecter \\
\hline H8 family & $\begin{array}{l}\text { father, } 41 \\
3 \text { boys, } 11,10,8\end{array}$ & no & flat & no & spartan & 520 & rejecter \\
\hline H9 family & $\begin{array}{l}\text { mother, } 41 \\
\text { father, } 45 \\
2 \text { boys, } 8,7\end{array}$ & no & flat & yes & carer & 520 & user \\
\hline
\end{tabular}

a study about how people live and interact with a domestic robot. The text briefly described that households were going to receive a Roomba vacuum cleaning robot over a period of several months, and that the study would take place in their home with the researcher visiting each household several times. We wanted to avoid giving a Roomba to people who were not at all interested in deploying a robot in their home. This fact has to be kept in mind when analyzing and interpreting the data and makes results not generalizable. The sample consisted of nine households with a total of 30 participants: 16 men and 14 women, 15 children (six months to 18 years old), and 15 adults ranging from 26 to 71 years old (mean age 43.6 years). More specifically, the study included three single-headed (one single parent) and six double-headed households (one couple without children). Each household $(\mathrm{H})$ profile is briefly described in the following:

H1 consists of a 40 year old single male participant without pets. Originally from France, he lives in an apartment in the periphery of town and works in the IT domain. He also programs in his leisure time.

$\mathrm{H} 2$ consists of a 71 year old single woman who is originally from Austria. Now retired, she used to work in the health care sector and has been living for more than 20 years in a small house with garden in the suburbs. She has a small dog and two tortoises. She barely uses her laptop and internet but is open though skeptical of new technology. When she has difficulties in using her computer or cell phone, she appreciates help from her younger friends.

H3 is a couple consisting of a 62 year old British woman and her 58 year old Swiss common-law spouse. They share a flat in the center of the city with two cats. Both describe themselves as not being much into technology but open to new developments as long as they are useful. While he is working in the media sector, she works independently for a company that sells organic products.

H4 consists of parents (40ies), two girls aged 10 and 8, and a cat. This German family lives in a house with garden in the periphery of town close to the lake. They describe themselves as open to new technologies but the mother is skeptical. She used to work in the health care sector but now stays at home. The father has a background in engineering but now does freelance management.

H5 consists of parents (40ies), 4 children (18 year old daughter, 15 year old son, 12 year old twin girls), and a dog. This Danish family lives in the periphery of town and is quite open to new technology. The father works in an international company while the mother stays at home.

H6 consists of the parents (late 20ies), the 5 year old son, 4 year old daughter, a 6 month old baby boy, and a cat. This Swiss family lives in the countryside, maintains an 


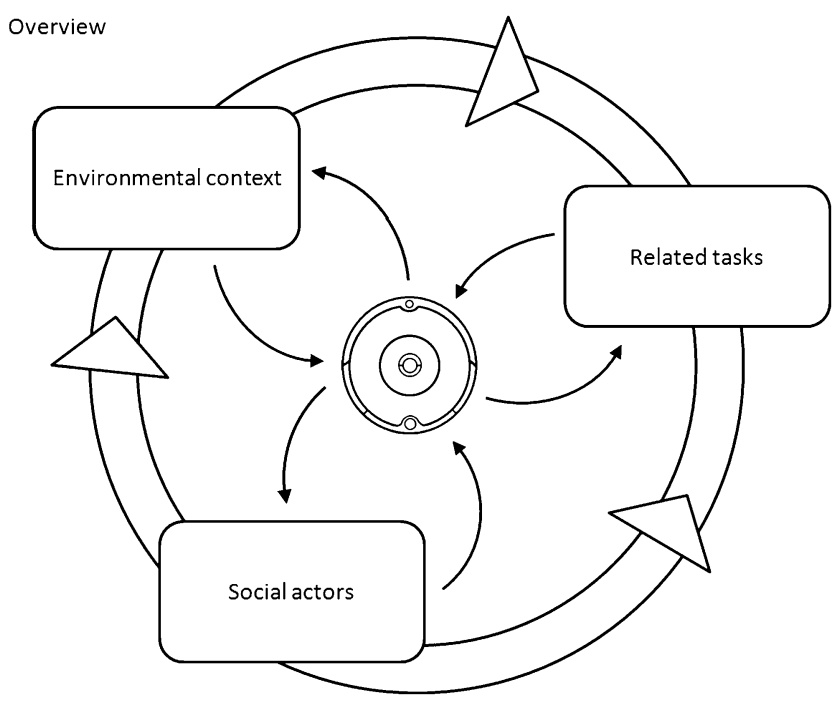

Fig. 1 Adapted and simplified version of the Domestic Robot Ecology framework, Sung et al. [33]. The overview of interactions between a vacuuming robot (in the middle), and the key attributes: the related tasks, the environmental context, and the social actors; which form together the ecology of the home

organic lifestyle, and uses new technology as long as it is practical (e.g. they do not have a TV). The father works as dentist and the mother manages her own teashop part-time in the town nearby.

H7 consists of parents (early 30ies), and a 1 1/2 year old son. This Swiss-French family lives in the center of the city and we would describe them as an 'early adopter' household, since they have all latest technologies in their home. They emphasize design and live an organic, healthy lifestyle. The father (Swiss) works as a freelance graphic designer, partly from his home office. The mother (French) works part-time in an advertising agency.

H8 consists of a single father (41 years old), and three boys $(8,10$, and 11 years old) who also live at their Japanese mother's place. This Swiss-Japanese family lives in a flat in the center of the city and we would describe them as an 'early adopter' household, based on the latest technology devices they are using. The father (Swiss) works as a teacher and has a background in robotics.

H9 consists of parents (40ies), and two boys ( 7 and 8 years). This Swedish-American family lives in an exclusive apartment in the suburbs with view on the lake. They have latest technologies in their home. The father (Swedish) is working in an international company and the mother (French-American) gives courses in an international business school. The family left the study after 5 months because they moved unexpectedly to another country. The data for the concluding 5 th visit is thus missing.

\section{Findings}

We integrated and structured results along the 'Domestic Robot Ecology' framework (DRE) [33]. We did this because first, the DRE provides a concrete structure to organize our observations, and second because it makes findings of two similar studies easy to compare. Through outlining similarities and differences we aim to extend previous work and contribute to a robust holistic framework of acceptance of domestic robots. Initially we wanted to develop our own model of domestic robot adoption. During data analysis and synthesis we saw that our results mainly support the DRE framework. This is why in the end we did not build another model but added data to an existing one. Figure 1 shows an adapted and simplified visualization of the DRE. It gives an overview of interactions between a vacuuming robot (pictured in the middle), the related tasks (such as cleaning), the environmental context of the home (physical and social space), and the social actors in the household. We use this simplified version to highlight at which stages of adoption process the robot impacts which key attributes. The reader can refer to more details in the original work [33].

The DRE gives a holistic view of the relationships that robots shape in the home and how these change over time. On one hand, the framework identifies four temporal stages of how households accept robots in homes: (1) pre-adoption, (2) adoption, (3) adaptation, and (4) use/retention (see Sect. 5). It also describes three key attributes that influence the interaction experiences across these temporal stages: physical and social space, social actors, and intended tasks [33]. Interactions between the robot, the task characteristics (vacuuming) (Sect. 4.1), environmental context (Sect. 4.2), and social actors (Sect. 4.3) are described in five relationships: the robot formed relationships as (1) a tool to perform tasks, (2) an agent that impacts the environment, (3) a mediating factor that motivates people to make changes in the environment, (4) a mediator that enhances social relationships within the household, and (5) an agent that engages with people in social events [33].

\subsection{Task Characteristics: Cleaning Routine}

According to Sung et al.[33], tasks refer to the activity that the robot is designed to perform (vacuuming and more generally cleaning). Domestic tasks are inter-related and therefore automating one task with a robot may bring changes to the connected tasks [33]. In the following, we describe and compare people's cleaning routine without and with the robotic vacuum cleaner (robotic VC). This data was collected through the paper-and-pencil diaries and rounded it out with interviews and day-reconstruction technique [16]. One of our aims was to understand each household's attitude toward cleaning and cleanliness. We expected the usage and adoption of the robotic $\mathrm{VC}$ would be impacted by 
the respective cleaning strategy. Therefore, we tried to categorize households according to the effort spent for cleaning the house. We are aware that this is a risky step given the small number of participating households.

Cleaning Strategies Without the Robot Based on people's remarks and our observations, we classified households according to their cleaning strategy. We derived the following four types, based on the motivation that a household has to keep the home clean, the efforts made and amount of time spent cleaning:

Spartan cleaners barely notice dirt and do very little about it. We would describe them as lacking motivation to clean, and hardly use the few cleaning tools they have (e.g. vacuuming once in two months). However, they feel comfortable. Cleaning is not important to them. (H1 and $\mathrm{H} 8)$

Minimalistic cleaners notice dirt around the house which makes them feel a little uncomfortable (which creates some intrinsic motivation to clean). They do what is necessary but not more. Vacuuming is done only when they have time to do so, e.g. once a week or once in two weeks. Cleanliness is not a priority. ( $\mathrm{H} 2$ and $\mathrm{H} 3$ )

Caring cleaners really care to have a clean and nice looking home to show visitors that they have a well working 'home ecosystem' (which creates some extrinsic motivation). They like to keep the home clean by vacuuming several times per week and they enjoy the resulting cleanliness. (H4, H5, and $\mathrm{H} 9$ )

Manic cleaners almost obsessively clean. They are very picky, notice every little piece of dirt, and probably constantly feel some pressure to clean or tidy up. Thus, they constantly engaged in cleaning and these tasks are a priority for them. Vacuuming happens more or less on a daily basis. (H6 and $\mathrm{H} 7$ )

This classification of cleaning strategies is not based on demographic factors but on our observations, interviews, and the analysis of each households' cleaning diaries. For instance, we discussed with people when we found dirty areas in their home and asked them how they felt about it. Interview questions asked whether one constantly felt the need to clean and tidy up or would be uncomfortable with leaving unwashed dishes when departing the house, for instance.

Comparison of Cleaning with and without the Robot Vacuuming was generally considered as an "annoying", "boring", "time consuming" repetitive task, that needs to be done over and over again. However, everyone in our sample described the vacuum cleaner (VC) as an important, indispensable cleaning tool. People didn't like its noise, its large size, heaviness, that it looked ugly, and needed to be plugged in to an electrical socket when used, which is not convenient for a device that needs to be moved around manually. Petowning households reported problems with the efficiency of the $\mathrm{VC}$ and some others with storing it. $\mathrm{H} 1$ and $\mathrm{H} 4$ needed to attach the VC inside the closet so that it did not fall out. This made it annoying to get the VC out of the closet and to put it back in which made it a tool that was not 'ready for use'. The 71 year old woman in $\mathrm{H} 2$ stored her VC in the basement, since it was mainly the cleaning lady who used it. However, when the woman needed it, she had to carry it upstairs, which was a heavy task for her and thus she tried to avoid it.

Future developments need to take aspects of how a device is used into account and develop appropriate design solutions. Domestic appliances that are in regular use, such as the VC, need to be easy to store and handle. Future domestic robots need to enable an overall positive user experience to become useful and valuable tools.

How did people in our study keep their homes clean, how did they use the VC and the robotic VC? In the following, we describe and compare people's cleaning routine in terms of who is cleaning, what, when, where, how, and why [13]. Overall, 634 distinct cleaning tasks were documented in the cleaning diaries, 193 activities of what involved the robotic $\mathrm{VC}$, and 65 used the VC.

Who: In most households, there was a clear division of labor between household members in matters of responsibilities of specific household tasks. Generally, our findings support the traditional (gender) roles of housekeeping [25, 27]. Women were the main housekeepers, independent from whether they were housewives, working part- or full-time. Women in our sample carried out $69 \%$ of the reported cleaning activities and $75 \%$ when only vacuuming is considered. Of the $75 \%$ of vacuuming sessions, however, $20 \%$ were done by the cleaning services, and another $10 \%$ by girls and female teens in the study. Surprisingly, women also turned out to be the Roomba's main users ( $67 \%$ of the $n=178$ valid cases) which was different in results from an online survey among Roomba users [29]. Asked, why she was Roomba's main user the mother in $\mathrm{H} 7$ explained: "Roomba is a vacuum cleaner, and since my husband never vacuums it's only me using it." Still, in comparison to the usage of the VC, men's proportion for Roomba usage was higher: men carried out $14 \%$ of all vacuuming with the traditional VC but $23 \%$ of all Roomba usages. What is notable, is the high proportion of vacuuming that was carried out by children and teens (21\%) in comparison to their share of all cleaning activities $(1 \%)$. In respect to teamwork, generally, when people cleaned, they did it on their own. Only about $10 \%$ of cleaning happened in collaboration of several people at the same time. Contrary to Sung et al. [33], in our study, the robotic $\mathrm{VC}$ did not enhance persistent collaborative cleaning. Initial effects of collaboration with the robot are addressed later (Sect. 5.2 'adoption phase'). 

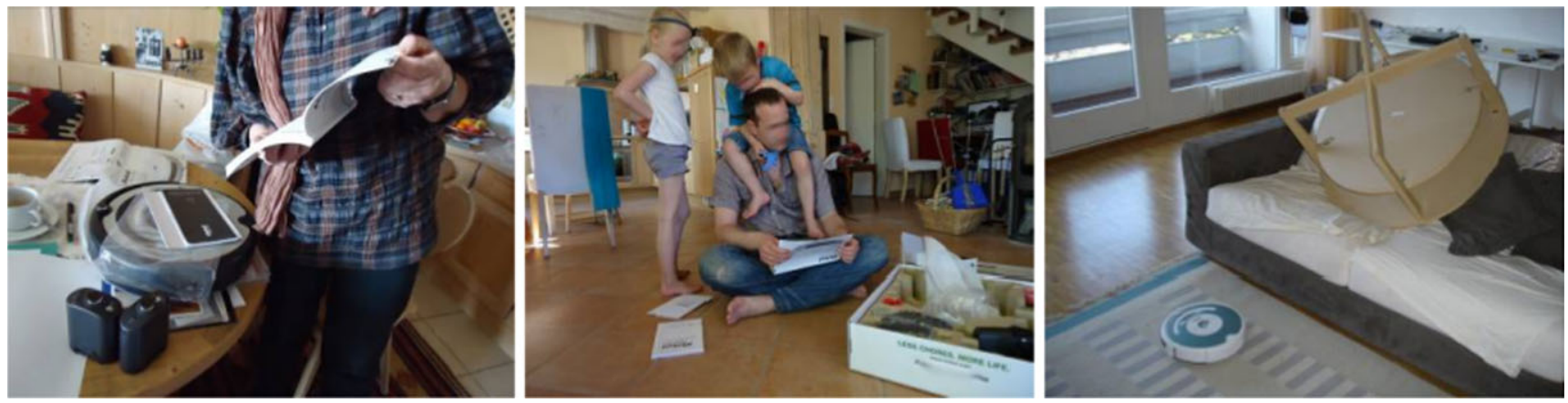

Fig. 2 An elderly participant reading the robot's manual (left); a family unpacking their vacuuming robot (center), and an example for adjustments of the home due to the robot (right)

In respect to people's age, two elderly people in our study (62 and 71 years) actively tried to avoid using the VC, due to its heaviness and their own physical restrictions. They both appreciated that the Roomba was much smaller and lighter than their traditional VC. We did not find differences in the frequency and amount of Roomba usage between elder and younger adults. However, how participants experienced the robot seemed to be affected by age, this was especially linked to usability. Age differences also played a role in how the robot was approached and used the first time. Children showed a great fascination for the robot and their intuitiveness in operating it was surprising. Even infants intuitively managed to switch on the robot and felt rewarded by the sound the robot makes when starting. Younger children tended to prefer the robot to the VC but teens were not interested in it and stopped using it after the first try.

Regarding the type of household, we cannot make general statements with a sample size of 9 households. However, analysis of the diary reports suggest that families used the Roomba more often for cleaning (the robot represented $35 \%$ of the various cleaning tools) than households without children (19\%). This is in accordance with Sung et al. [29] who found that households with children expressed significantly greater satisfaction with the Roomba's performance than households without children. We did not find differences in the amount and frequency of the robotic VC use in respect to whether the household benefited from a cleaning service or had a pet. However, these aspects shaped people's expectations of and hopes for the robot.

What: Half of the reported tasks were 'small things', such as cleaning the dishes (or loading the dishwasher) (19\%), wiping the table (18\%), tiding up something (14\%), or cleaning up crumbs from the floor $(11 \%)$. In addition to that, $23 \%$ of the household tasks concerned the laundry, folding clothes, or ironing. Surprisingly, overall only about $10 \%$ of all cleaning tasks involved the VC. During the course of the study, the proportion of cleaning activities that involved the VC decreased over time from $17 \%$ before the Roomba was deployed, to $15 \%$ at two months after the introduction of the robot, to $8 \%$ after six months. We think that the study itself might have triggered additional vacuuming activities in the beginning of the study. Similar to the VC usage, the proportion of Roomba usage (among the other cleaning tools in the household) decreased over time; the robot was used much more frequently during the first phase.

When: There was a tendency for people to clean more often on Sundays ( $18 \%$ of $n=634$ cleaning activities). This was especially true for the usage of the VC ( $26 \%$ on Sundays). However, Roomba usage was distributed more equally over the week with a peak on Wednesday (20\%). This confirms Sung et al.'s finding that the robotic VC helps people clean more regularly [33]. Concerning the time of day, participants carried out most cleaning tasks during the morning (46\% from 5-11 am), in comparison to $24 \%$ in the afternoon (1-5:30 pm), and finally $27 \%$ in the evening (6-10:30 pm). A similar distribution was found for vacuum cleaning as well as for Roomba usage. Whereas some of the households had a clear schedule (e.g. Sunday morning after breakfast), others did cleaning in a more opportunistic fashion when it was needed or they felt uncomfortable [11]. Most cleaning activities were related to meals.

On average, people cleaned 26 minutes, however $53 \%$ of all cleaning activities took in between 1-15 minutes. People spend a bit longer for vacuuming: usually between 20-30 minutes but still $27 \%$ of the reported vacuuming sessions took 60 minutes or longer. The amount of time and effort spent on cleaning differed significantly between the households but was surprisingly unrelated to the amount of dust that we noticed in each home. In contrast to vacuum cleaning, it was surprising that one third of the $n=141$ valid Roomba usages did not take longer than 15 minutes. This reflects the fact that people tended to stop the robot manually after a short period of time instead of letting it finish and return to its charging station itself.

Where: More often than anywhere else in participants' homes, cleaning took place in the kitchen (58\%), followed by $11 \%$ in the bathroom, and $10 \%$ in the living room (see 
Table 2 A comparison of where people clean, with the vacuum cleaner (VC), and with the Roomba; percentages in each column do not sum to $100 \%$ as not all possible locations are listed

\begin{tabular}{lccc}
\hline Where & $\begin{array}{l}\text { General } \\
\text { cleaning }\end{array}$ & $\begin{array}{l}\text { VC } \\
\text { usage }\end{array}$ & $\begin{array}{l}\text { Roomba } \\
\text { usage }\end{array}$ \\
\hline Kitchen & $58 \%$ & $17 \%$ & $35 \%$ \\
Bathroom & $11 \%$ & $35 \%$ & $2 \%$ \\
Living room & $10 \%$ & $10 \%$ & $28 \%$ \\
Children room & $6 \%$ & $17 \%$ & $17 \%$ \\
Bedroom & $4 \%$ & $14 \%$ & $10 \%$ \\
\hline
\end{tabular}

Table 2). However, only about $17 \%$ of the vacuuming happened in the kitchen, but $35 \%$ in the bathroom, and another $17 \%$ in the children's room. Further, the Roomba was used in the living room ( $28 \%)$, and the bedroom (10\%). People avoided using the robotic $\mathrm{VC}$ in the bathroom $(2 \%)$ which was the favorite room for the traditional VC (35\%). People explained to us that they were afraid that there could be wet spots in the bathroom and the robot could get damaged.

How: In most cases, people vacuumed 'room-by-room'. Most participants wanted to use the Roomba similarly to how they used their VC, which has also been found in a study on matching a vacuum robot's path planning to user expectations [19]. People imagined using the robot in one room, passing only once over every spot and they expected the robot to work better than their VC in less time. However, a father who had a background in robotics (H8) had more realistic expectations about the robot's capabilities than the other participants. Overall, there was no common strategy for using the robot. As we did not give instructions, we let people experiment themselves and observed the first usage. At the later visits, we asked how and why they used the robot as they did. In H1, H6, and $\mathrm{H} 7$ usage strategies changed over time. It seemed that these households had found their optimal way of using the robot after several attempts whereas the other households were not willing to spend the effort in learning how to use the robot in an optimal way and gave up after some disappointment (see Sect. 5.3).

The four defined categories of cleaning strategies (spartan, minimalistic, caring, manic), served well to explain how a household cleaned but were not transferable to Roomba usage. With traditional vacuuming, spartan and minimalistic cleaners planned their vacuuming sessions in advance, e.g. H1 had a monthly alert on his smart phone to remind him of vacuuming. In contrast, caring and manic cleaners vacuumed regularly, more or less on a daily basis. We also expected that the frequency of Roomba usage would impact a household's cleaning strategy. However, this was not the case. H1, who vacuumed once per month, turned out to use the robotic $\mathrm{VC}$ on a daily basis and put great effort in making it work well, whereas $\mathrm{H} 7$ who vacuumed every day, tried out the robot a couple of times but then refused to use it. These and other observations highlight that the robot was used as an independent tool and differently from a classic VC.

How people cleaned did not seem to be related to whether they had children or were pet owners. Each household complained about specific problems related to cleaning and used different strategies to keep efforts as low as possible. For example, $\mathrm{H} 4$ lived in a house with garden. To keep the ground floor clean, they always entered through the garage. Several households (H2, H4, H6, H7, H9) had a broom or dustpan in the kitchen to be able to quickly clean up the kitchen floor without having to get out the VC.

Why: We asked participants why they cleaned in the manner they cleaned, for example they tended to store their VC in a 'remote place' such as the furthest corner of the closet, despite the fact that it was used regularly. Participants were not very clear in their answers but mentioned the $\mathrm{VC}$ was an ugly and unpleasant tool that they didn't like at all and thus tried to "keep it out of sight". One participant said: "I don't want to see the VC every time I open my closet and be reminded of the need to vacuum." Another one said: "I need the VC every single day to clean up around the table. Sure, it would be easier to have it just right next to the table. But it wouldn't look nice. I don't want my VC or any other cleaning tool to be that present." We conclude that traditional VCs would need a lot of improvements to be considered as a more pleasant tool.

Intermediate Essential: A comparison of cleaning activities shows that people use a robotic $\mathrm{VC}$ in a different way than a classical VC. Both tools are preferred according to their own characteristics (e.g. suction power, immediate availability) and the characteristics of the area which needs to be cleaned (e.g. surface, obstacles). The difference in usage might suggest that a robotic vacuum cleaner might not a priori be able to replace a traditional vacuum cleaner.

\subsection{Environmental Context: Physical and Social Space}

In Sung et al.'s DRE, the environmental context of the home, is understood as the physical, social, as well as technical space of a home [33]. This comprises the indoor physical environment (floors, rooms, furniture), the social lifestyle of the household, as well as the configuration and organization of technologies in the home. With mobile and ubiquitous technology in the home, the location of a technology has a new meaning. The ubiquitous spatial presence [33] of autonomously moving robots impacts upon the broader physical and social space. Previous work suggests that the environmental context of the home is likely to impact on how a domestic robot is used and experienced [11] as well as vice versa and our observations generally confirm this. 
Physical Space: Participants expected the robot to work equally well in the entire house and intended to use it everywhere. However, the physical layout of the home impacted the robot's performance. Two households (H3, H7) had door sills that the robot was not able to pass over. Whereas $\mathrm{H} 7$ felt Roomba's inability to overcome this obstacle made the robot less usable, $\mathrm{H} 3$ acknowledged that this meant she could easily keep it in the kitchen. Households with stairs in their home didn't feel this constrained how they used the vacuuming robot, however, usage data showed that Roomba was used slightly more often in homes without stairs. Another aspect that constrained where and how the robot was used was the location of electrical sockets, as the robot's charging station needs to be plugged in so that the robot could automatically go back to it. In three homes there was a lack of electrical sockets in the living room and in two of them, the height of the sockets meant that the charging station could not be placed on the ground because the cable was too short. This was clearly impractical and it made it difficult to use the robot in its intended way because it constrained its autonomy. In the end, this negative experience hindered people in integrating the robot in their cleaning routine.

Regarding different kinds of floors, homes in our sample included parquet floor, tiles, as well as various types of carpets. The robotic VC worked equally well on each of the surfaces, however people reported difficulties when Roomba was moving from tiled or parquet floor to carpet (the robot dropped dust or even got stuck). This shaped the experience with the robot and was a crucial factor of acceptance/adoption (see Sect. 6). Not all participants were willing to (re-)move the 'difficult' carpets. For instance, an elderly woman $(\mathrm{H} 2)$ who had Persian carpets was afraid the robot might leave marks on them and only used the robot in the kitchen where there was no Persian carpet.

In general, participants found it easier to use the Roomba in a home characterized by large open spaces and few separating walls. Additionally, participants were positively surprised to see the robot cleaning underneath furniture where they could not reach with the traditional VC and placed the Roomba intentionally right in front of the bed or closet. This shows that the physical layout of the home can also trigger specific use cases with a robot.

Social Space: How people were using the robot was further impacted by the social space of the home. Some homes were characterized by a harmonious arrangement of furniture and decor objects. The specific lifestyle of $\mathrm{H} 3$ made it impossible for the woman to use "something as artificial as a robot" in her painting room. She explained the robot would not fit the decor of the room and when she once tried out using it there she felt that it was disturbing the mood. The robot's design interfered with the social space of several other homes. Characteristics of the robotic VC design seemed to be more important than the classical VC. This could be due to the fact that in contrast to a usual VC, Roomba was not hidden in a closet when not in use but always visible and present. Further it moved autonomously through the home and some people found this intruded their privacy. Consequently, they didn't like to use it when they were not at home and able to "observe it". This however, was not a good solution because the robot's vacuuming noise was annoying for most of the people. Only one participant (H2) described she liked the robot's noise because it gave the impression it was " $a c$ tually working" and "doing its job": "It's nice when the Roomba moves around the house making little noises and talking to me occasionally." The other participants decided to use the robot while they were not at home. However, not everybody felt comfortable about this. Some people had difficulties with having the robot's charging station visible in a prominent open space, such as the living room. The living room is a highly social space, where people relax, host guests and have conversations, it serves to present a specific lifestyle. People did not want to have either the robot or its charging station visible in the living room. As the mother in H9 explained "Still, this is a vacuum cleaner and you don't want to have your vacuum cleaner next to your dining table when you are having dinner or friends are coming over. It looks too much like work!"

\subsection{Social actors: The Robot within the Household}

According to the 'Domestic Robot Ecology', social actors are the living members in the home, such as householders, guests, and pets. Sung et al. [33] divide social actors into 'users' who interact with robots on a regular basis to complete a task, and 'non-users' who do not regularly use but engage in social activities with this technology. Pets can be regarded as part of the group of social actors. Social responses to robots (e.g. anthropomorphism) are, amongst other things, based on how people perceive and relate to the robot [7]. To capture people's perception of the Roomba, we let them evaluate it in respect to various topics. We were interested in whether and how people's perception changed over time and how far it would be related to individual and external factors.

People's Perception of the Robot over Time Participant's perception of the robot was assessed using a recurring questionnaire that was integrated in the semi-structured interviews at each household visit. All present family members were asked to rank the robot on a 7-point Likert scale (1-7) according to the aspects intelligence, usefulness, ease of use, fun, attachment, impact and overall impression. The method was adapted from Sung et al. [30] and Scopelliti et al. used similar scales [26]. To enhance discussion and keep the situation as natural as possible, participants of the same household were interviewed collectively, thus children were not 
Table 3 Means (M) and standard deviations (SD) for each topic over five times ( $T 1-T 5)$ on a 7-point Likert scale (1-7). Repeated measures ANOVA with time as within subjects factor, $n=15$

\begin{tabular}{|c|c|c|c|c|c|c|c|c|}
\hline Topic & $\begin{array}{l}\mathrm{M} \\
\mathrm{SD}\end{array}$ & $T 1$ & $T 2$ & $T 3$ & $T 4$ & $T 5$ & $\begin{array}{l}F \\
(4,56)\end{array}$ & $\mathrm{p}$ \\
\hline \multirow[t]{2}{*}{ Intelligence } & & 3.9 & 4.1 & 4.2 & 3.8 & 3.3 & \multirow{2}{*}{2.2} & \multirow{2}{*}{0.09} \\
\hline & & 1.6 & 1.6 & 1.6 & 1.7 & 1.3 & & \\
\hline \multirow[t]{2}{*}{ Usefulness } & & 4.9 & 5.2 & 5.1 & 4.5 & 4.2 & \multirow{2}{*}{2.6} & \multirow{2}{*}{0.05} \\
\hline & & 1.4 & 1.0 & 1.2 & 1.9 & 1.9 & & \\
\hline \multirow[t]{2}{*}{ Ease of use } & & 5.6 & 6.1 & 6.3 & 6.3 & 6.1 & \multirow{2}{*}{2.2} & \multirow{2}{*}{0.08} \\
\hline & & 1.2 & 0.6 & 0.7 & 0.8 & 1.0 & & \\
\hline \multirow[t]{2}{*}{ Fun } & & 4.0 & 4.1 & 4.6 & 4.1 & 4.3 & \multirow{2}{*}{0.7} & \multirow{2}{*}{0.5} \\
\hline & & 1.6 & 1.6 & 1.7 & 1.6 & 1.4 & & \\
\hline Attachment & & \multicolumn{7}{|c|}{ no valid data due to wrong measurement } \\
\hline \multirow[t]{2}{*}{ Impact } & & 3.5 & 4.2 & 4.0 & 3.2 & 2.8 & \multirow{2}{*}{3.4} & \multirow{2}{*}{0.02} \\
\hline & & 1.6 & 1.4 & 1.1 & 1.3 & 1.5 & & \\
\hline \multirow{2}{*}{$\begin{array}{l}\text { Overall } \\
\text { impression }\end{array}$} & & 5.2 & 5.2 & 5.0 & 4.9 & 4.5 & \multirow{2}{*}{1.3} & \multirow{2}{*}{0.30} \\
\hline & & 1.2 & 1.1 & 1.2 & 1.3 & 1.5 & & \\
\hline
\end{tabular}

separated from their parents, and participants evaluated the robot in front of each other. This could have caused some biases, which should be kept in mind when interpreting the data. Participants filled out the questionnaire at five time points: ( $T 1)$ before they had seen the robot, $(T 2)$ right after they had unpacked and tried out the robot for the first time, (T3) two weeks after they had received the robot, (T4) two months afterward, and (T5) after six months living with the robot. Participants' ratings were compiled in a spreadsheet, to one decimal place (two coders agreed on the interpretation of each mark, e.g. if the mark was understood as 5.4 or 5.5). Preliminary results after $T 3$ have been published already [9]. We used repeated measures ANOVA tests with time (5 time points) as within-subjects factor. Further, we defined gender, family code, and adopter group as betweensubjects factors. Gender had two categories (female/male), family code had nine categories (H1-H9), and adopter group had three levels (rejecter/user/adopter) according to how far at the end of the study a household was still using the robot for cleaning or not. Rejecters didn't use the robot any more, users sporadically used it but would not buy it for themselves, whereas adopters integrated the robot in their routine and could not imagine living without it. In general, the results of these statistical analysis are not strong, since only a small number of valid ratings $(n=15)$ were considered (Table 3). For this reason, we could also not statistically analyze age differences.

Overall, there was a 'positive' peak for most of the ratings at $T 2$, right after participants used the robotic VC for the first time. This suggests that the sample had a rather positive experience when trying out the robot and most of the expectations ( $T 1$ ) were initially met (or even exceeded). However, most ratings became less positive after six months with the robot, with slight variations during the study. In more detail:

Perceived Intelligence: Overall on a scale from 1-7, participants rated the robot as 'somewhat intelligent' (values from 3.3-4.2) but were not really convinced about it being smart. The rating did not change significantly over time (see Table 3). Interestingly, at all five time points, male participants rated the robot as more intelligent (average 4.5) than females (average 3.4), however, this difference was not significant. When asked why they thought Roomba possessed intelligence, men more often referred to its abilities to detect obstacles and stairs, and being able to recharge itself. Contrary, women referred to its rather limited vacuuming function and found it not as intelligent because "It doesn't see where the dirt is, it sometimes leaves it, it can't be smart!". There was no significant difference between adopter groups $(F(2,12)=0.2, p=.79)$, however, adopters rated the robot more intelligent at each time point.

Perceived Usefulness: Participants rated the functional robot as quite useful (values from 4.2-5.2), however, values decreased significantly over time. Women rated the robot less useful (average 4.4) than men (average 5.2) (difference not significant.) This again was due to the fact that women (as the main users) evaluated the robot's vacuuming power whereas men regarded more generally that the robot could help cleaning and would thus be a useful device. A significant difference was found for the adopter groups $(F(2,12)=6.7, p=.01)$ : adopters rated Roomba significantly more useful (average 6.1) than users (average 4.6), and rejecters (average 3.9). This observed difference is in accordance with models of the adoption of technology [22, 37] and acceptance of robots [14].

Perceived Ease of Use: People found the robot very easy to use (values from 5.6-6.3) and the only thing they would change about it, was how one had to empty the dust bin. Still some participants had difficulties in using the infrared walls, that come with some Roomba models, and especially the elder participants did not know how to assemble the charging station. There was no significant gender difference in the perceived ease of use, however, data suggests that with growing experience, especially women rated the robot as even easier to use (contrary, men rated the robot less usable in the end of the study, probably because they had not gained much experience with it). Accordingly, adopters rated the robot significantly easier to use (average 6.7) than rejecters (average 5.9) $(F(2,12)=4.6, p=.03)$. This confirms again traditional models of technology adoption and acceptance of robots [22, 37] and acceptance of robots [14].

Experienced Fun: Participants rated the robot as 'somewhat fun' (values from 4.0-4.6). Again, there was a qual- 
itative gender difference (not significant), in the sense that the experienced fun remained quite stable for male participants, whereas it tended to decrease for female participants. Males described the robot more as a 'fun gadget' than females, who referred to it as "In the end, Roomba is a cleaning tool and it is not really fun to use it.". In respect of the three adopter groups, there was no significant difference for the ratings $(F(2,12)=0.3, p=.73)$, however, at each time asked, adopters rated having experienced more fun (average 4.5) than rejecters (average 3.9).

Emotional Attachment: The ratings for people's emotional attachment are unfortunately not consistent because we discovered they were strongly related with the respective instructor who conducted the interview process. The two instructors described 'attachment' in an inconsistent way during the study and at different households. Because of this we cannot use the data for attachment for this study.

Perceived Impact on the Household: Participants estimated the robot's impact on the household significantly different at different points of time. While in the beginning at $T 2$ (right after first usage) and T3 (after two weeks), people believed Roomba could maybe change something in the household, after two and six months ( $T 4$ and $T 5$ ) they more or less lost their initial hope the robot could evoke some changes. There was a significant difference for perceived impact of the robot between adopter groups $(F(2,12)=5.4$, $p=.02$ ). Adopters rated the robot's impact higher (average 4.6) than users (average 3.7), and rejecters (average 2.9).

Overall Impression: People's expectations before they used the robot $(T 1)$ were quite high (5.2, on a scale from 1-7 with 7 as the most positive) and though not significant, men expected even more (5.7) than women (4.8). However, with time, participant's overall impression constantly got worse, even though with an average rating of 4.5 in the end it was still rather positive. The three adopter groups rated their overall impression significantly different $(F(2,12)=23.3$, $p \leq .05$ ): adopters (average 6.2), users (average 4.5), rejecters (average 3.8). Interestingly, before they had seen the robot, the later adopters had the lowest expectations (4.5), whereas rejecters had the highest (5.7). We could interpret, that those with the highest expectations had a rather negative first experience since the robot probably did not meet their expectations, while those who expected less were maybe positively surprised.

Social Activities with Roomba The robot, even though functional, created some few social dynamics that had implications also on the participant's social life in general. It has already been described that domestic robots can serve as socially interactive agents $[10,28]$. In our study, people also engaged in social activities with the robot, however, we would like to stress, that these social dynamics were quite rare and not persistant. For example, previous work described people gave a name to their vacuuming robot and liked to customize it $[28,32]$. However, we did not observe any activity of customizing the robot and only one woman (H3) gave a name to her robot ("Elvis") which seemed to be more for fun than actually reflecting a kind of social attachment to the robot. We think that no participant perceived the robot as a social agent, as it is suggested in the DRE framework [33].

A similar rather weak social interaction that only occurred during the stage of initial adoption was collaborative cleaning. This finding is in contrast to Sung et al.'s conclusion that the robot would have the social impact of "making cleaning a concern for everyone in the household" [11,33]. As described earlier, the robot was not able to encourage in a long term way household members to clean who did not clean before. Only in the very beginning did people assist the robot in cleaning (notably children). Children collected crumbs and put them right in front of the robot, they put up the bathroom carpet or chairs that hindered the robot from passing through (Fig. 7 center part). This immediate activity was observed in all families with younger children but also in the elderly single woman initially started collecting dust while the robot was vacuuming. She explained that she didn't want to see the robot working on its own and would feel bad when she didn't at least help him a little. However, she stopped using the robot completely after about 3 months.

Another immediate activity that the robot encouraged particularly children to do was to build walls out of obstacles and furniture to prevent the robot from going somewhere where they didn't want it to go or to keep it somewhere. However, people also stopped this activity soon. Children up to the age of about six years kept on putting toys on top of the robot or offered their stuffed animal a ride. The positive impact of children and pets on the experiences with Roomba has already been described by [29]. Younger children interacted with the robot physically (Fig. 7 left part) and emotionally by playing and experimenting with it. For example, they let it bump into parts of their body, carried it around, and arranged objects as a circuit or labyrinth for the robot. Some children (mostly boys) made the robot part of their games and plays, e.g. they let it make a footrace with the baby that just learned to crawl or played hide and seek with the robot. Some also found creative ways of integrating it in their games with and without other toys: Roomba as a shark and the sofa as the boat where one is safe; Roomba as a spaceship with lasers. The pets in our study reacted in different ways to the robot. Though the pets were curious (Fig. 7 right part), two cats and one dog were afraid, one dog tried to bite the robot and only $\mathrm{H} 3$ derived fun from watching their two cats' playing with it. Dogs barked at Roomba (H5) when it was vacuuming or anxiously hid behind the owner's feet (H2). 
Nevertheless, the robot also served as a mediator for social interactions with persons who did not belong to the household, such as work colleagues or guests. During the first weeks, when participants hosted guests, they showed the robot and gave demonstrations. This enhanced discussion or served as entertainment. Especially male participants described they liked to show their friends the "fancy new robot" they had in their home. Female participants rather liked to receive feedback from their friends which is described a usual activity in the process of adopting innovative technology [22]. One participant (H1) reported the robot would have helped him to socialize at his workplace as colleagues were asking him for news about the robot and his experiences. Also within a household, Roomba and the fact of taking part in the study triggered discussions about future technologies, robotics, cleanliness, and the cleaning routine. It seemed to create an awareness of the otherwise rather unnoticed routine of cleaning of things lying around. Most people reported Roomba made them more aware of their clutter and encouraged them to tidy up.

We found the most interesting social relationship to the robot with a 71 years old single woman who lived with a dog and two tortoises. She was socially active and regularly met friends. Her dog seemed to be one important social interaction partner and she talked directly to it as if it were a human and treated it in quite human-like ways (anthropomorphism). When she saw and tried out the robotic VC, she compared it to her dog and told us (after hesitation) she would feel emotionally attached to the robot. Though she did not give it a name, she talked directly to it and cared for it more than one would have to 'care' for an object that can be switched off. For instance, she phoned us because she felt her Roomba could lack attention during the time she wanted to go on holidays, and asked us whether she should give it to her neighbor so that it would still be in use. For her, the robot seemed to be a companion and she confirmed this several times.

\section{Adoption Process}

Concerning temporal stages of adoption, our study generally supports Rogers' 'Diffusion of Innovation' [22] as well as Sung et al.'s 'Domestic Robot Ecology' (DRE) framework [33]. In the following, we integrate the qualitative observations from our 6-month study into the latter initial framework of domestic robot adoption. This step of analysis is a second main contribution of our work. We are able to outline major similarities and some qualitative differences in how households in Sung et al.'s study and our study adopted (or rejected) their vacuum cleaning robot. This is an important finding, as the two studies have been conducted with different models of the robot and in a different cultural region. Consequently, it shows that the DRE, though still an

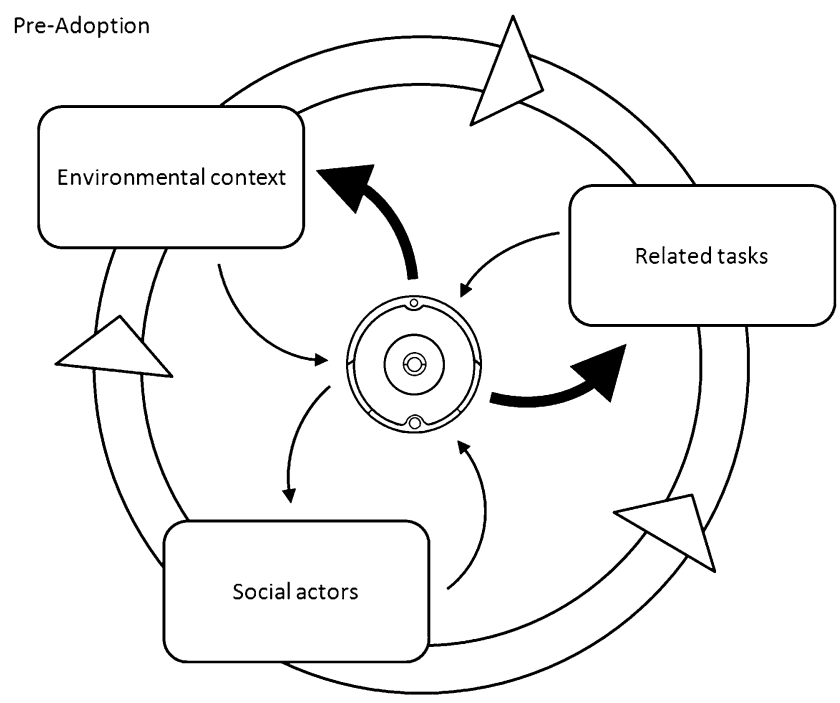

Fig. 3 Pre-adoption stage: main interaction between the robot (in the middle) and the key attributes are highlighted with a bold arrow; people expect the robot to work as a tool that performs vacuuming (robot impacts related task); people expect the robot to improve the cleanliness of the home (robot impacts environment); inspired from [33]

initial framework, can in a sufficiently robust way describe the process of adopting a domestic service robot.

According to the four temporal steps described in Sung et al.'s DRE, our findings are structured as follows:

1. Pre-adoption: Forming expectations

2. (Initial) Adoption: Getting the first impressions

3. Learn/Adaptation: Learning affordances and limitations

4. Use and Retention: Routine practice and maintenance

We observed different durations for these four steps for different households. It seemed that some households already formed a strong initial decision to adopt or reject the robot right after the first tryout while others seemed undecided for about two months or even longer. In general, most things happened during the first two weeks and two months but only few dynamics have been observed during the last four months. In the following, we describe how each of the adoption phases was characterized in our study.

\subsection{Pre-adoption}

Pre-adoption (see Fig. 3) refers to a phase that is temporally before the purchase of the system (in our study, this is the period from when we confirmed to a household the participation in the study until the second visit, when we brought the robot with us). Rogers describes this phase involving two steps: knowledge and persuasion [22]. In this phase, people learn that there exist domestic vacuum cleaning robots and gain some understanding and first knowledge of it. People form expectations and attitudes towards vacuuming robots, e.g. they expect the robot to work as a tool 
that performs vacuuming (see Fig. 3 bold arrow, robot impacts related task), and how it might improve the cleanliness of the home, thus the robot impacts the environment (see Fig. 3 bold arrow). These are the main interactions occurring in the pre-adoption stage. People's expectations formed during this stage can have a strong impact on their initial reaction to it and powerfully shape the experience [11]. Our participants had very different expectations about robots and the Roomba, in particular. The assumptions that they made about possible robot functions were based on previous experience with robots (when available), on articles they read about robots in journals or newspaper (mostly about industrial robots, robot toys or technical aspects), or on media (science-fiction, novels). Participants with a lower affinity for technology had more difficulties in describing their expectations about the robot. However, generally, people's uncertainty about what domestic robots are capable of and the lack of experience with robots, created skepticism. People were not at all sure what they should expect of a vacuum cleaning robot. Participants were curious to try out 'a robot' in their home, also the elder participants. Some participants already thought about trying out a robotic VC before because they had heard about it but the financial barrier was too high to just purchase one without really knowing what it would be able to do. Non of the households had tried out a Roomba before but two families had had experiences with other robots (LEGO mindstorms (H9), lawn-mowing robot(H6)). When using Roomba the first time, children in H6 thought then it was going to cut the carpet's 'hair'. How powerfully expectations can shape the initial experience with a device can also be illustrated with the reaction of a 8 years old girl in $\mathrm{H} 4$. After having unpacked, set up and switched on the robot, she folded her arms, looked down and went upstairs to her room. We later asked her what had happened and she explained she was sad because she expected the robot to have arms, and a head and be more human-like.

Most participants expected the robot to be bigger but less noisy as it actually was. All hoped Roomba would make their home cleaner and take over some part of the vacuuming (or replace the VC). Participants wished vacuuming would become less cumbersome, they could save time and do other things while the robot was vacuuming (multitasking). Especially pet owners wanted to decrease the amount of pet hair. Households with children had concerns whether the robot could work properly due to the children toys on the floor and the expected fascination the robot would have for the children. Parents also hoped the robot could motivate the family members to tidy up. Two parents wanted to use Roomba to introduce robotics to their children because they believed robots would be part of the future and the children should get in touch with this. Mothers of younger children were concerned about the robot might attract too much the child's attention and it could be a harm for the infant or contrary the

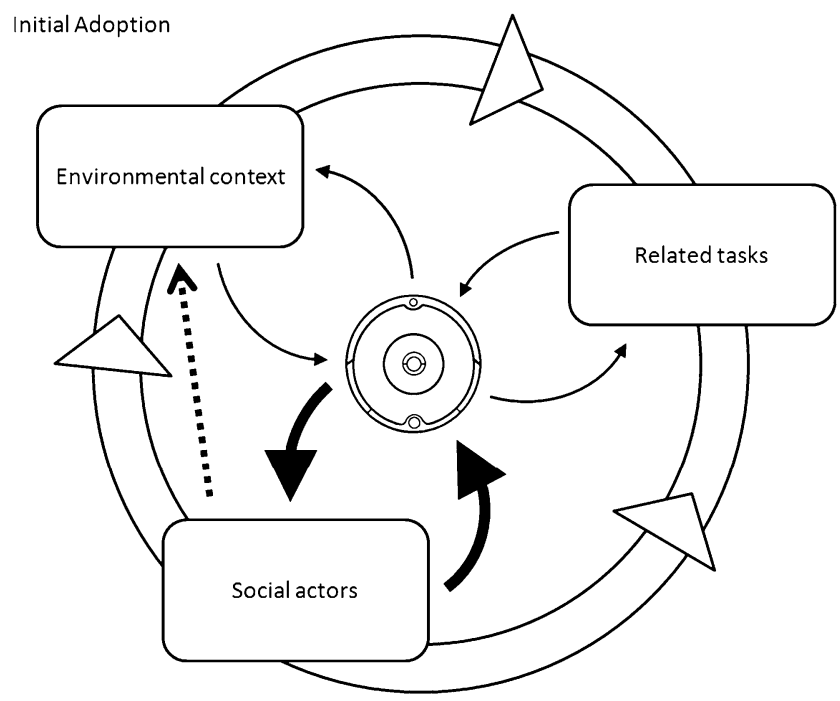

Fig. 4 In the initial adoption stage: people watch and observe the robot (social actors relate to the robot); the robot makes people talking about it and evokes an impression (robot impacts social actors); the robot encourages people to make changes to the environment (dashed arrow); inspired from [33]

robot might get damaged when the child would play with it. Elder participants were much more concerned about the usability of the robot and were more hesitant when using it the first time. Expected challenges were mostly that the robot would not clean well, e.g. in corners or around the table and some were also afraid the robot could fall down stairs, leave marks on the floor or bump heavily into furniture.

\subsection{Initial Adoption}

The initial adoption phase describes people's first impressions and initial reactions to the robot and includes the first interactions with Roomba (see Fig. 4). In this stage, main effects included people watching the robot (see Fig. 4, bold arrow) and also, the robot evoking an impression in the social actors (see Fig. 4, bold arrow). Additionally, we observed participants making changes to the environment (see Fig. 4, dashed bold arrow) encouraged by the robot.

How did participants approach the robot and interact with it during the first usage? We structured each household's initial use of the robot in several steps. A comparison revealed common stops and differences in how the robot was approached. Two families opened the packaging and assembled the parts collectively (H5, H6). In contrast to this in other families there was one person who gave instructions from the manual while the others were sticking parts together (H4, H7). In two households the parents were passively watching how the children unpacked and set up the robot (H8, H9). Not all households had a look at the manual: some immediately pushed the start button after having unpacked the robot, some read all or some parts of the manual before switching it on (Fig. 2 left and center part), and 
some asked questions to the passively observing researcher. What all households did (most before switching the robot on) was that they checked its parts and tried to find out how it actually worked: people turned the robot around, touched the brushes and wheels and discovered the sensors and front bumper. Some made a couple of adjustments to the space, to ensure the robot would not damage something or get damaged, e.g. they put away cables or a sheet of paper that was lying on the floor, or pushed chairs aside. After this phase of quick preparation which took between 1-20 minutes (but was skipped by some households) participants pressed the 'clean button' to switch on the robot (we charged its batteries first). When the robot started to move, most participants stepped back and some children started screaming and jumping around. In all households the robot was carefully observed and verbal comments were made on its abilities ("Oh! It slows down in front of an obstacle!") or in hope to guide it around ("But go over there then, there are still some crumbs!"). While the robot was running, some of the households had to solve further issues (calm down the dog, push away delicate objects) or were looking for more information (in the manual or online). In all households, participants discovered the robot, interacted with it and tested how it would react to some disturbance, for instance. The first time the robot was touched while it was moving, people let it bump into their foot and just after they were sure that nothing bad would happen, they also kneed and touched it with their hands. People picked up the robot while it was moving to see what would happen, and some even put it on a table to see whether it would fall down when it approached the rim. All these little experiments helped people to gain knowledge about how the robot was working and to form an initial decision. Overall, these first interactions with the robot revealed a lot about social roles, responsibilities, the household's process of introducing new products in the home, and their attitude towards the Roomba. Nevertheless, people's initial reaction to the robot remained difficult to capture. Though it was already the second visit at each household, we had the impression that some participants felt a bit uncomfortable and might have behaved unnaturally due to the observer. Above all, children's naturalness in discovering the robot was notable. Most reacted with great enthusiasm for the moving thing but little infants were also afraid and started crying or wanted to be back on the mother's arm.

However, it has already been described that the first phase with a new product is shaped by novelty effects $[8,18,22$, 30]. Novelty effects are the first responses to an artifact and characterized through high levels of attention and interest, and increased usage. In respect to domestic robots, Sung suggests that strong effects can be observed within the first two weeks with a robot and that after about two months usage beyond novelty effects can be observed [30]. Our study confirms this suggestion. How people used and described

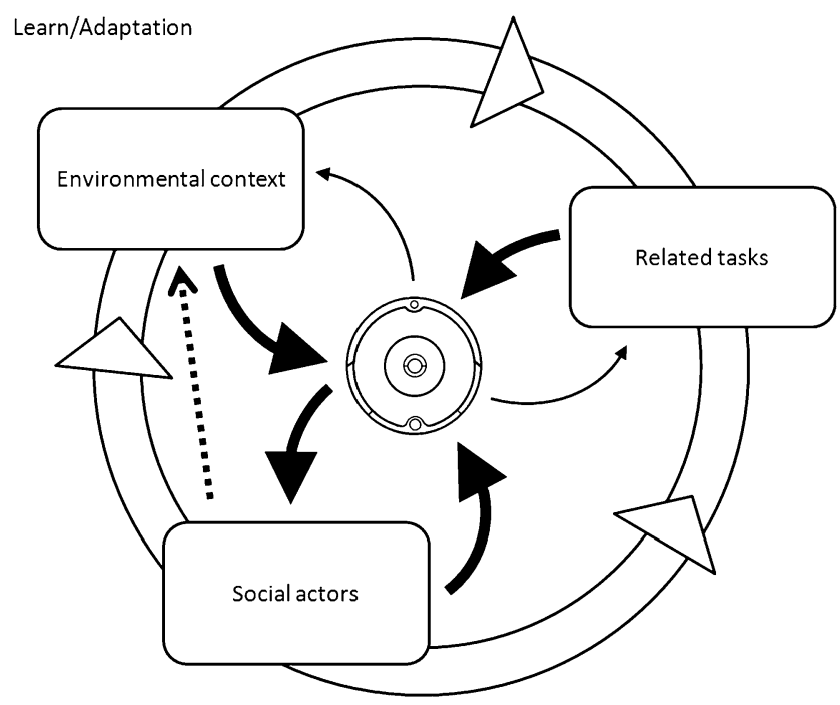

Fig. 5 In the learn and adaptation stage: people's attitude towards the robot impacts how much they try it out (social actors relate to the robot); the robot entertains and makes people giving demonstrations for guests (robot impacts social actors); the robot encourages people to make lasting changes to the environment (dashed arrow); the environmental context impacts how the robot is tried out (environment impacts robot); people need to maintain the robot which impacts its performance (related tasks impact robot); inspired from [33]

the robot during the first two weeks was shaped by its novelty. It was seen as a 'fancy new device', shown to other people, and tried out in a variety of ways. When visiting the households after they lived with the robot for two weeks, most of them still described a fascination for it, used it frequently and assessed its limitations. This changed after two months. The majority of the households decreased their frequency of Roomba usage, and described it as "just another cleaning tool". After six months, two households (H7, H8) had completely stopped using the robot ('rejecters'), four households (H2, H3, H4, H9) used it sporadically but could not really take advantage of it and would not buy it ('users'), and three households (H1, H5, H6) had integrated the robot in their cleaning routine ('adopters').

\subsection{Learn and Adaptation}

According to Sung et al. during the learn and adaptation period (see Fig. 5), people try to learn more about the artifact by experimenting with complexity in use and compatibility with the current environment, and make necessary changes to better incorporate the device [33]. Through this stage, which Rongers [22] labels 'implementation', people determine whether they will accept or reject further use. The main interaction effects during this stage are highlighted in Fig. 5. In addition to the mutual interactions between the social actors and the robot (which had already occurred in the previous stage), now as experimenting how the robot works begins, 'cleaning' (as 'related task') and the physical and 
social context of the home ('environmental context') have a direct impact on the robot (bold arrows in Fig. 5.

Interestingly, as already described in [29, 32, 33], the robot encouraged people to make a variety of adjustments to their home (mostly during the first two weeks of the study). For example, people put away obstacles (wires, cables, toys, decoration, etc.), moved furniture (e.g. so that the robot was able to pass in between two shelves), and tidied up. One family (H5) also bought covers for the cables of the TV and play console and took quite some time to assemble them in the living room. The mother said the cables had annoyed her for a long time already, especially when vacuuming but that the robot motivated her to actually make this adjustment. A similar statement came from the woman in $\mathrm{H} 2$, who kept stacks of magazines and newspapers for more than two years in the living room: "I felt so sorry for the robot when it bumped into the stack again and again that I just had to put it away. Actually, I was thinking of tidying them up before but never found it was urgent. Now I am happy it's out of my view. I have more space now." The robotic VC had a strong impact on the physical environment of people's homes ('mediating factor'), more than a usual VC and triggered activities to adjust that environment. Another solution to make the apartment 'Roomba safe' was to adjust things every time right before the robot was used. The whole six months during the study, when $\mathrm{H} 1$ was using the robot, he placed the coffee table on the sofa and put away the chairs (Fig. 2 right part). During the first days it happened quite often that when he came back home after work he found the robot stuck somewhere. He learned what had caused the error and fixed the specific aspect. After one week he had made his flat 'Roomba-safe' and was happy that he did not have to vacuum manually anymore. $\mathrm{H} 7$ wanted to let Roomba vacuum the ground floor during night, when they were sleeping upstairs. This would have solved the problem of having the children interacting to much with robot while it was "doing its job". However, the robot was too noisy and woke up the parents. The family changed their strategy to switching on the robot during the day before leaving to go for a walk or play in the garden. However, some households were not willing to engage in the effort of learning how to optimally use the robot and their process of adoption stopped in this stage. Consequently, they decided to not use the robot any longer.

\subsection{Use and Retention}

This step indicates the period when people begin to show a routine with the robot and seek to confirm its 'existence' in the household (see Fig. 6). In other words, the user "seeks reinforcement of an innovation-decision that has already been made, but the individual may reverse this previous decision if exposed to conflicting messages about

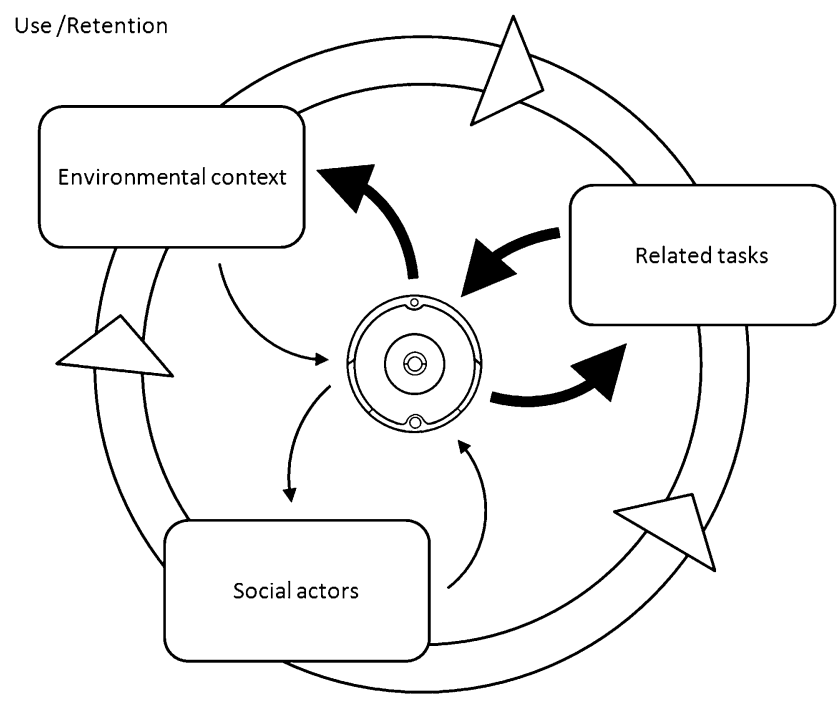

Fig. 6 In the use and retention stage: the robot is used as a tool to vacuum (robot impacts related tasks); people need to maintain the robot (related tasks impact robot); the robot vacuums regularly and thus changes the environment (robot impacts environment); however: people stopped making changes to the environment and as it has become optimal, it does not impact anymore how the robot is used; people stopped giving robot demonstrations and do not relate socially to it anymore but view it as an everyday tool; inspired from [33]

the innovation" [22]. The main interaction that occurs during this stage is related to how far the robot improves the state of cleanliness in the home (see Fig. 6, bold arrow to environmental context). As the robot is now regularly used as a tool to clean, it has a strong impact on the related task.Contrary, how well people maintain the robot impacts how well it can work (see Fig. 6, bold arrows related tasks).

For the three households that adopted the robot, this phase began after about two months. Different use cases had already been tried out by then and the optimal way of using the robot was found. Participants then stuck to their strategy and it became more or less a routine to run Roomba every morning when leaving the home $(\mathrm{H} 1, \mathrm{H} 5)$, and/or additionally after meals, when leaving with the children or before going to sleep (H5, H6). In H6 it had become a routine that the father emptied Roomba's dust bin in the evening so that the mother could use it again the next day. During this stage, Roomba was not perceived as a 'fancy new robot' anymore but as 'just another cleaning tool'. Depending on the adopter group (adopter, user, or rejecter) in the use and retention stage, households were either able to confirm the positive impact that the robot had as a cleaning tool (H1, H5, H6), or were still not sure about its value as an additional vacuum cleaner but used it occasionally $(\mathrm{H} 2, \mathrm{H} 3, \mathrm{H} 4, \mathrm{H} 9)$, or had not even tried to use it again after the initial disappointment (H7, H8). It was interesting that four of the households had not formed a clear decision during the six months. When asked whether these sporadic users would buy a Roomba, 

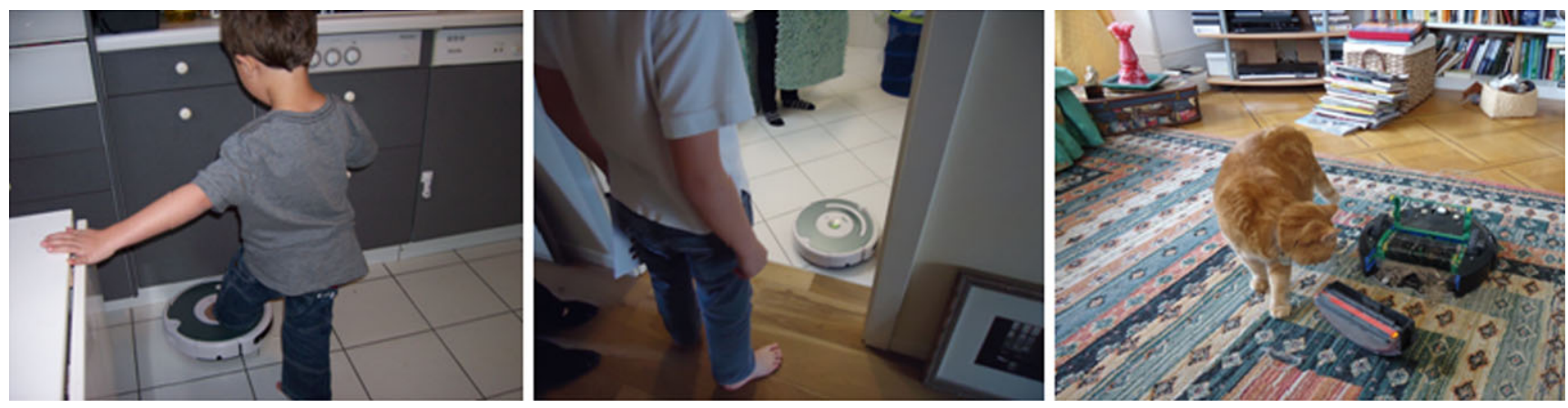

Fig. 7 Children touched the moving robot first with their feet and then with hands (left); an example of initial assistance with cleaning, a boy picking up the carpet to allow the robot to go everywhere (center); a cat exploring the opened robot (right)

they all answered "no", however, all of them wanted to keep the robot though.

\section{Implications}

In this section, we suggest seven implications that we derived from our observations and participant's feedback. These seven implications are adapted to functional domestic service robots but also match most of the factors that are described in traditional theories for the adoption of technology $[6,22,37]$. We hope these suggestions can help developers to go one step toward acceptable, long-term HRI and can provide them useful insights into human factors and user needs for a vacuum cleaning robot in people's homes.

Practical Utility/Usefulness: One of the probably most important aspect is the practical utility (usefulness, Rogers: relative advantage) of a domestic robot. Perceived usefulness is defined as the degree to which a person believes that using a particular technology will enhance the respective task (or daily life in general). This includes decreasing the time for doing the task, more efficiency, and accuracy. The majority of households (6 out of 9) did not perceive the robot as useful, as they didn't feel their home became cleaner or they could save some time (Rogers: observable results).

Physical Space/Environmental Context: As already described, some physical layouts constrain the way a vacuum cleaning robot can work and navigate around. Tiny rooms with a lot of corners and homes with door sills are not suitable for Roomba, as it decreases its efficiency or can make it impossible for it to move around autonomously. Besides this, households generally didn't like to make adjustments to their home to enable the robot to work. For people living alone it seemed easier to adjust the space but as soon as several people share one place changes are not made easily and it would cause some effort to get everybody's agreement (e.g. to put the problematic carpet away).
Ease of Use/Learn how to use Device: Perceived ease of use refers to the degree to which a person believes that using a particular technology will be free of effort. It includes the expected effort required to utilize the system and the effort of using it (Rogers: Simplicity). It has been described that a huge performance benefit can outweigh the effort that users expect to spend [6]. Though the robot was fairly ease to use, it required to learn how to optimally use it, namely by just letting it do its job without big interventions from the user side. The difficulty for most participants was to overcome their expectation that the robot would vacuum more efficient than their traditional vacuum cleaner in even less time. The robot needs to be used in a different way than a usual vacuum cleaner but not everybody was willing to learn how to use it.

Compatibility with Habits/Routine: Another huge barrier when it comes to integrating a robot into a daily routine is the aspect of its compatibility with a person's beliefs and attitudes in respect to the context of the system. Cleaning routines are based on personal beliefs and attitudes towards cleaning and cleanliness. These are subjective judgments and certainly not easy to consider in the design process of domestic service robots. However, how a person understands herself and her environment impacts how a robot is used and accepted or rejected. One participant believed no one could do the cleaning as efficient and properly as herself and thus she did not accept any help with it, neither from her husband, nor from a cleaning service, nor from a robot. The robot was simply not compatible with her personal beliefs. (Rogers: compatibility with existing values and practices).

Personal Value/Attachment/Reliability: Some devices in a home might not be very practical or even hard to use, however, they find their place as they hold a great personal value (e.g. evoke attachment). The elderly woman in $\mathrm{H} 2$ could not derive much practical utility from the robot and she also was afraid of doing something wrong with it. However, she liked to keep it because she simply "liked" it, when it was moving and required her 'help' when it was tangled up in the 
carpet. Closely related to this kind of attachment is reliability which plays an important role in HRI. When people did not trust/rely on the robot, they didn't want to leave the room/home when the robot was switched on. However, this does not meet the robot's intended way of use.

Social Compatibility/Subjective Norm: According to [39] the subjective norm is a person's belief that most of her important others think she should (or should not) perform the behavior in question (e.g. using a vacuuming robot). H1's work colleagues usually did not talk much to him but suddenly showed interest in his new robot, which triggered conversations and even led $\mathrm{H} 1$ to invite some other colleagues to his place to give him/her a robot demo. This encouraged $\mathrm{H} 1$ to keep on using the robotic $\mathrm{VC}$, as he experienced a positive social impact.

Economical Compatibility/Financial Benefits: Last but not least, a domestic appliance needs to be affordable. Not only its shelf price but also the financial costs for maintenance are taken into account. Roomba requires new brushes fairly often when used daily. As we gave the robot for free to our participants they did not have this financial barrier but all of them measured the gained benefits to the expenses it consumed. An important aspect also in respect to the environmental responsibility concerns the energy consumption of the robot. People do not easily accept to leave a device plugged in all the time as costs for electricity constantly increase. A study on electricity consumption and cleaning efficiency can be found in [34].

Another important aspect in making the decision upon adopting a domestic service robot is the possibility of trying it out without having significant negative implications (financial costs, e.g.). Rogers refers to this as 'trialability' [22] and we think that especially with innovative robotic technologies for the home, this is a crucial factor, as it can decrease people's uncertainty with (domestic) robots.

\section{Conclusions}

We described in detail mainly qualitative observations from a 6-month long ethnographic study with nine households in which we deployed a vacuum cleaning robot. The results along with the implication that we can draw from our study are, however, limited. This is mainly due to the very small sample size. Further, the households were using two different models of Roomba, which might impact have an impact. Despite these limitations, our qualitative descriptions can contribute to an understanding of Human-Robot Interaction in the real world. Our study also adds new and rich examples from households around Lausanne in Switzerland to Sung et al.'s 'Domestic Robot Ecology', which is based on data from the US. This addition helps it become a more robust framework in the domain and a useful tool for others.
To conclude, we would like to highlight some key aspects about living with a functional robot at home. We were surprised to find that only three out of the nine households adopted the robot in a durable way though we recruited only households that were generally interested in a vacuum cleaning robot. At this moment, we believe that, as soon as robots and humans are sharing the same space, they need to adapt to each other to be a good match: People need to learn how to use a robot in an effective way, by building trust in it and by letting it do its intended task. This of course requires that the robot is an acceptable agent that meets moral and ethical standards, is safe and trust-able. Several key aspects for domestic service robots and the acceptance of domestic robots, that we found through our study can be summarized as follows:

\section{People are curious to try out a robot in their home.}

People of all ages are generally open to trying out a functional robot in their home, as long as they don't have to expect a risk. Their understanding of what domestic functional robots are able to do and how they can be used is not very clear and people's expectations are still based on media. The lack of previous experience with a robotic system creates uncertainty but also curiosity.

\section{Cleaning strategies are deeply rooted habits.}

How people clean is something very private and seems to be based on personal convictions. Though different strategies of cleaning and attitudes toward cleanliness did not determine whether the cleaning robot was adopted, some personal convictions are not compatible with having a robot doing part of the domestic labor.

A robot does not profoundly change cleaning roles.

A robotic $\mathrm{VC}$ does not change well defined cleaning roles in a household, thus, when the mother has been the main responsible for vacuuming, the father will not suddenly engage lastingly in vacuuming with the robot. Men liked the robot more for its symbolic value while women appreciated its function to work as a vacuum cleaner.

Roomba is not a replacement of the vacuum cleaner. A vacuum cleaning robot does not (yet) replace the traditional VC. However, it can reduce the amount of vacuuming sessions and helps people to keep their homes clean. [35]

Beliefs are more important than the environment.

The environmental context of the home certainly plays a role in how a robot is and can be used and further impacts the process of adoption of a domestic robot. However, personal attitudes and underlying household rules are even more important and first of all a robot needs to be practical in the eye of the user.

Roomba is not perceived as a robot but as a tool. People's general attitude towards robots and robotics does not seem to change when using a simple functional 
robot such as Roomba. However, the experience broadened most people's mind and more importantly, how the robot appeared changed qualitatively over time from 'fancy new robot' to 'just another cleaning tool'. This confirms the existence of novelty effects and their strong effects on human-robot interaction and perception which both are likely to change over time and with growing experience with the system. After novelty effects have worn off, Roomba was not perceived as a robot but as a tool.

The social impact of functional robots is overestimated. People tend to basically anthropomorphize even a simple functional robot, by talking to it directly or by using communication traits that are comparable when relating to a pet or other human. However, the phenomenon wears off when people become familiar with the robot. The social impact of a vacuum cleaning robot seems to be overestimated. Apart from children and one single elderly woman, people did not view or treat the robot as a social agent.

We hope that more long-term studies on HRI and the adoption of robots in domestic spaces will be carried out, so that in the future meaningful robotic solutions will be acceptable as everyday objects.

Acknowledgements We thank all our participants for their engagement in the study as well as iRobot and iRobotics GmbH Switzerland for their support. Thanks also to the reviewers and to JaYoung Sung. This research was supported by the Swiss National Science Foundation through the National Centre of Competence in Research Robotics.

\section{References}

1. Bartneck C, Suzuki T, Kanda T, Nomura T (2006) The influence of people's culture and prior experiences with aibo on their attitude towards robots. AI Soc 21(1-2):217-230

2. Bartneck C, Kulić D, Croft E, Zoghbi S (2008) Measurement instruments for the anthropomorphism, animacy, likeability, perceived intelligence, and perceived safety of robots. Int J Soc Robot 1(1):71-81

3. Bell G (2001) Looking across the atlantic: Using ethnographic methods to make sense of Europe. Intel Technol J Q3:1-10

4. Corbin JM, Strauss A (1990) Grounded theory research: procedures, canons, and evaluative criteria. Qual Sociol 13(1):3-21

5. Dautenhahn K, Woods S, Kaouri C, Walters ML, Koay KL, Werry I (2005) What is a robot companion-friend, assistant or butler? In: IEEE Proceedings IROS'05, pp 1192-1197

6. Davis FD (1989) Perceived usefulness, perceived ease of use, and user acceptance of information technology. MIS Q 13(3):319-340

7. Epley N, Waytz A, Cacioppo JT (2007) On seeing human: a threefactor theory of anthropomorphism. Psychol Rev 114:864-886

8. Fernaeus Y, Haakansson M, Jacobsson M, Ljungblad S (2010) How do you play with a robotic toy animal?: A long-term study of pleo. In: Proceedings IDC'10. ACM, New York, pp 39-48

9. Fink J, Bauwens V, Mubin O, Kaplan F, Dillenbourg P (2011) People's perception of domestic service robots: same household, same opinion? In: Mutlu B, Bartneck C, Ham J, Evers V, Kanda T (eds) Social robotics, vol 7072. Springer, Berlin, pp 204-213
10. Forlizzi J (2007) How robotic products become social products: an ethnographic study of cleaning in the home. In: Proceedings HRI'07. ACM, New York, pp 129-136

11. Forlizzi J, DiSalvo C (2006) Service robots in the domestic environment: a study of the roomba vacuum in the home. In: Proceedings HRI'06. ACM, New York, pp 258-265

12. Gaver B, Dunne T, Pacenti E (1999) Design: cultural probes. Interactions 6(1):21-29

13. Ha TS, Jung JH, Oh SY (2005) Method to analyze user behavior in home environment. Pers Ubiquitous Comput 10(2-3):110-121

14. Heerink M, Kröse B, Evers V, Wielinga B (2009) Measuring acceptance of an assistive social robot: a suggested toolkit. In: IEEE Proceedings RO-MAN'09, pp 528-533

15. Hüttenrauch H, Severinson-Eklundh K (2003) Fetch-and-carry with CERO: observations from a long-term user study with a service robot. Tech Rep IPLab-213, Royal Institute of Technology (KTH), Stockholm

16. Kahneman D, Krueger AB, Schkade DA, Schwarz N, Stone AA (2004) A survey method for characterizing daily life experience: the day reconstruction method. Science 306(5702):1776-1780

17. Kanda T, Ishiguro $H$ (2005) Communication robots for elementary schools. Tech rep, CiteSeerX. http://citeseerx.ist.psu.edu/viewdoc/ summary?doi=10.1.1.152.3557

18. Kanda T, Hirano T, Eaton D, Ishiguro H (2004) Interactive robots as social partners and peer tutors for children: a field trial. HumComput Interact 19(1):61-84

19. Kim H, Lee H, Chung S, Kim C (2007) User-centered approach to path planning of cleaning robots: analyzing user's cleaning behavior. In: Proceedings HRI'07. ACM, New York, pp 373-380

20. Mutlu B, Forlizzi J (2008) Robots in organizations: the role of workflow, social, and environmental factors in human-robot interaction. In: Proceedings HRI'08. ACM, New York, pp 287-294

21. Pantofaru C, Takayama L, Foote T, Soto B (2012) Exploring the role of robots in home organization. In: Proceedings HRI'12. ACM, New York, pp 327-334

22. Rogers EM (1995) Diffusion of innovations. Simon and Schuster, London

23. Sabelli AM, Kanda T, Hagita N (2011) A conversational robot in an elderly care center: an ethnographic study. In: 2011 6th $\mathrm{ACM} / \mathrm{IEEE}$ international conference on human-robot interaction (HRI), pp 37-44

24. Salvini P, Laschi C, Dario P (2010) Design for acceptability: improving robots' coexistence in human society. Int J Soc Robot 2(4):451-460

25. Schön-Bühlmann J, Freymond C, Koch D, Renfer JP (2006) Le ménage pour lieu de travail: le temps consacré au travail domestique et familial et son estimation monétaire. Actualités OFS 7790600, Office Fédéral de la Statistique (OFS), Neuchatel

26. Scopelliti M, Giuliani MV, Fornara F (2005) Robots in a domestic setting: a psychological approach. Univers Access Inf Soc 4(2):146-155

27. Sullivan O (2000) The division of domestic labour: twenty years of change? Sociology 34(3):437-456

28. Sung J, Guo L, Grinter RE, Christensen HI (2007) "My roomba is rambo": intimate home appliances. In: Krumm J, Abowd GD, Seneviratne A, Strang T (eds) Proceedings UbiComp'07, vol 4717. Springer, Berlin, pp 145-162

29. Sung J, Grinter RE, Christensen HI, Guo L (2008) Housewives or technophiles?: Understanding domestic robot owners. In: Proceedings HRI'08. ACM, New York, pp 129-136

30. Sung J, Christensen HI, Grinter RE (2009) Robots in the wild: understanding long-term use. In: Proceedings HRI'09. ACM, New York, pp 45-52

31. Sung J, Christensen HI, Grinter RE (2009) Sketching the future: assessing user needs for domestic robots. In: IEEE Proceedings RO-MAN'09, pp 153-158 
32. Sung J, Grinter RE, Christensen HI (2009) "Pimp my roomba": designing for personalization. In: Proceedings CHI'09. ACM, New York, pp 193-196

33. Sung J, Grinter RE, Christensen HI (2010) Domestic robot ecology. Int J Soc Robot 2(4):417-429

34. Vaussard F, Bonani M, Rétornaz P, Martinoli A, Mondada F (2011) Towards autonomous energy-wise RObjects. In: Hutchison D et al (eds) Towards autonomous robotic systems, vol 6856. Springer, Berlin, pp 311-322

35. Vaussard F, Fink J, Bauwens V, Rétornaz P, Hamel D, Dillenbourg $P$, Mondada F (2013) Lessons learned from robotic vacuum cleaners entering in the home ecosystem. Robotics and Autonomous Systems. (Submitted)

36. Venkatesh A (1996) Computers and other interactive technologies for the home. Commun ACM 39(12):47-54

37. Venkatesh V (2000) Determinants of perceived ease of use: integrating control, intrinsic motivation, and emotion into the technology acceptance model. Inf Syst Res 11(4):342-365

38. Venkatesh V, Bala H (2008) Technology acceptance model 3 and a research agenda on interventions. Decis Sci 39(2):273-315

39. Venkatesh V, Davis FD (2000) A theoretical extension of the technology acceptance model: Four longitudinal field studies. Manag Sci 46(2):186-204

40. Young JE, Hawkins R, Sharlin E, Igarashi T (2008) Toward acceptable domestic robots: applying insights from social psychology. Int J Soc Robot 1(1):95-108

Julia Fink is a PhD student in Human-Robot Interaction at EPFL. She has a multi-disciplinary background in Media, Technology, Communi- cation, and Interaction Studies. Her research interests are social implications and acceptance of robots in daily life.

Valérie Bauwens is an ethnographer, studying the process of adoption of technology in homes and work spaces. She has a background in business administration and psychology and has been working for 10 years in finance and business development before she founded Human Centricity in 2010. She applied her expertise in ethnographic research in several projects with EPFL.

Frédéric Kaplan worked ten years for Sony inventing new artificial intelligence algorithm for the AIBO robots. He joined EPFL in 2006 to design new kinds of interactive furniture and robotic objects. In 2008 he founded OZWE a company selling robotic computers.

Pierre Dillenbourg is professor of learning technologies at EPFL. Former teacher in elementary school, he graduated in educational science (University of Mons, Belgium). He obtained a $\mathrm{PhD}$ in computer science from the University of Lancaster (UK), in the field of educational applications of artificial intelligence. His work covers various domains of computer-supported collaborative learning (CSCL), ranging from novel interfaces for face-to-face collaboration (interactive furniture, tangibles, paper computing) to more cognitive projects on dual eye tracking. 